\title{
SUCESSÃO NA AGRICULTURA FAMILIAR: PRODUÇÃO CIENTÍFICA BRASILEIRA NA ÁREA DE ADMINISTRAÇÃO PỦBLICA E DE EMPRESAS, CIÊNCIAS CONTÁBEIS E TURISMO (2004-2016)
}

\author{
Vanessa Gleica Cantú Gris ${ }^{1}$ \\ Sandra Mara Stocker Lago² \\ Loreni Teresinha Brandalise ${ }^{3}$
}

\section{RESUMO}

Este estudo objetiva apresentar um levantamento da produção científica brasileira publicada em periódicos do sistema Qualis da área de Administração Pública e de Empresas, Ciências Contábeis e Turismo sobre a sucessão na agricultura familiar no período de 2004 a 2016. Para tanto, realizou-se uma pesquisa bibliográfica tendo como base de pesquisa os periódicos avaliados no sistema Qualis da área, cadastrados na plataforma Sucupira da Capes (Coordenação de Aperfeiçoamento de Pessoal de Nível Superior). As buscas ocorreram no período de outubro a dezembro de 2016 e considerando os critérios de exclusão adotados foram selecionados 34 artigos que compõem a amostra desta pesquisa. Os resultados evidenciam a restrição da produção acadêmica na área e maior concentração de publicações oriundas da região sul do país. No contexto geral os estudos abordaram a renda como principal limitador da permanência do jovem no campo, além da fragilidade da infraestrutura do campo, dificuldade no acesso à educação, ausência de políticas públicas, desigualdade de gênero e visão negativa dos pais quanto ao futuro dos filhos na propriedade. Como fatores que contribuem para a sucessão na agricultura familiar percebeu-se forte influência da pluriatividade e diversificação da produção, qualificação profissional, envolvimento com as cooperativas, incentivo da família e perfil empreendedor dos jovens.

Palavras-chaves: agricultura familiar, levantamento científico, sucessão.

\footnotetext{
${ }^{1}$ Graduada em Secretariado Executivo (UNIOESTE). Mestrado em Administração (UNIOESTE). E-mail: vanessacantu90@hotmail.com.br.

2 Graduada em Administração (UNIOESTE) e Informática (UNIOESTE). Mestrado em Engenharia de Produção (UFSC). Doutorado em Desenvolvimento Regional e Agronegócio (UNIOESTE). Professora do Programa de Pós-Graduação Mestrado Profissional em Administração (PPGA) da Universidade Estadual do Oeste do Paraná (UNIOESTE). E-mail: smstocker@uol.com.br.

${ }^{3}$ Graduada em Administração (UNIOESTE). Mestrado em Engenharia de Produção (UFSC). Doutorado em Engenharia de Produção (UFSC). Professora do Programa de Pós-Graduação Mestrado Profissional em Administração (PPGA) da Universidade Estadual do Oeste do Paraná (UNIOESTE). Email: lorenibrandalise@gmail.com.
} 


\title{
FAMILY FARMING SUCCESSION: BRAZILIAN SCIENTIFIC PRODUCTION SURVEY IN PUBLIC AND BUSINESS ADMINISTRATION, ACCOUNTING AND TOURISM AREA (2004-2016)
}

\begin{abstract}
This study aims to present a survey of Brazilian scientific production published in scientific journals of the Qualis system, concerning the Public Administration and Business, Accounting and Tourism area, about family farming succession from 2004 to 2016. Therefore, a bibliographical research was perfomed, in which periodicals evaluated in the Qualis system of the area, registered in the Sucupira platform from CAPES (Coordenação de Aperfeiçoamento de Pessoal de Nível Superior) were the basis of the research. The research took place from October to December 2016 and considering the exclusion criteria adopted, 34 articles were selected to constitute the sample of this research. The results show restriction of academic production on family farm succession and higher concentration of publications from the southern region of the country. Generally, it was verified that the studies indicate the income as the main limitation to keep young people in rural areas, besides the fragility of the rural infrastructure, difficulties in education access, lack of public policies, inequality of gender and negative views from parents about the future of their children in the property. As factors that contribute to family farming succession, it was noticed a strong influence of the pluriactivity and production diversification, professional qualification, involvement with the cooperatives, family incentive and young entrepreneur profile.
\end{abstract}

Keywords: family farming, scientific survey, succession.

\section{INTRODUÇÃO}

Frente à representatividade da agricultura familiar no contexto econômico, bem como suas características sociais peculiares, que tradicionalmente buscam manter o patrimônio familiar por diversas gerações, a preocupação com a questão sucessória dessa categoria social vem ganhando espaço no campo acadêmico.

A nova conjuntura desse modelo de produção é marcada pela migração da população rural para o meio urbano, sobretudo da população jovem, comprometendo a sucessão dos estabelecimentos rurais familiares e consequentemente a continuidade da agricultura familiar enquanto categoria social.

A questão sucessória e herança agrícola afetam não apenas as dimensões familiares, mas também o setor agrícola de forma abrangente, portanto, a transferência intergeracional é entendida como fundamental para a sustentabilidade e desenvolvimento da agricultura global (LEONARD et al., 2017).

$O$ destaque que a agricultura familiar vem ganhando nas últimas décadas, principalmente no que tange ao desenvolvimento rural brasileiro, está relacionado à sua importância econômica e social, pois além de produzir alimentos básicos que abastecem a população tem grande relevância na articulação rural-urbana (COSTA, 2011).

Apesar de sua importância econômica e social, Spanevello et al. (2011) confirmam as dificuldades desse modelo de produção em garantir sua reprodução social devido ao crescente fluxo migratório dos jovens rurais para o meio urbano. 
A fim de contribuir para o entendimento amplo da temática, embasado nas contribuições dos estudiosos da área, este estudo objetiva apresentar um levantamento da produção científica brasileira publicada em periódicos do sistema Qualis da área de Administração Pública e de Empresas, Ciências Contábeis e Turismo sobre a sucessão na agricultura familiar no período de 2004 a 2016 . Assim, define-se a seguinte questão de pesquisa: quais os principais resultados da produção científica brasileira sobre a sucessão na agricultura familiar publicada em periódicos científicos da área de Administração Pública e de Empresas, Ciências Contábeis e Turismo no período de 2004 a 2016 ?

\section{AGRICULTURA FAMILIAR}

Agricultura familiar é o sistema de produção em que os proprietários rurais exercem a função de gerência ou administração de seus estabelecimentos e ao mesmo tempo são os próprios trabalhadores. Esse sistema de produção tem significativa importância econômica em diversas cadeias produtivas e é o maior segmento em números de estabelecimentos no país (ABRAMOVAY et al., 1998).

As propriedades agrícolas familiares brasileiras perfazem um total de 4.367.905 estabelecimentos, representando $84,4 \%$ dos estabelecimentos do país e ocupam $24,3 \%$ da área total das propriedades agropecuárias do país. A média dessas propriedades é de 18,37 hectares, enquanto que as não familiares concentram uma média de 309,18 hectares (IBGE, 2006).

Esse modelo de produção responde por aproximadamente $70 \%$ dos alimentos consumidos no país (BRASIL, 2015) e de acordo com Abramovay et al. (1998) também é responsável pela geração de empregos, preservação do meio ambiente e manutenção das relações sociais entre os indivíduos, sendo assim apontada como um capital social de grande valor ao meio rural e ao próprio desenvolvimento como um todo.

No Brasil, o debate sobre a agricultura familiar ainda é recente, Schneider e Niederle (2008) clarificam que ao se consultar a bibliografia contemporânea sobre os processos sociais rurais e agrários, verifica-se que a incorporação da expressão agricultura familiar emergiu a partir da década de 1990.

A evidência da agricultura familiar no país é associada por Spanevello (2008) com a implantação do Programa Nacional de Fortalecimento da Agricultura Familiar (PRONAF) em 1995. Esse programa de políticas públicas específicas para os agricultores familiares, que trouxe o reconhecimento social da categoria "agricultor familiar", foi criado devido à pressão política dos sindicatos dos trabalhadores rurais e demais movimentos sociais ligados ao campo, como a Confederação Nacional dos Trabalhadores da Agricultura (CONTAG).

A partir desse movimento, percebeu-se a consolidação da agricultura familiar enquanto categoria, com destaque à Lei no 11.326, que estabelece as diretrizes para a formulação da Política Nacional da Agricultura Familiar e Empreendimentos Familiares Rurais. De acordo com essa lei considera-se agricultor familiar e empreendedor familiar rural, aquele que pratica atividades no meio rural, atendendo simultaneamente, os seguintes requisitos:

I - não detenha, a qualquer título, área maior do que quatro módulos fiscais:

II - utilize predominantemente mão de obra da própria família nas atividades econômicas do seu estabelecimento ou empreendimento; 
III - tenha percentual mínimo da renda familiar originada de atividades econômicas do seu estabelecimento ou empreendimento, na forma definida pelo Poder Executivo;

IV - dirija seu estabelecimento ou empreendimento com sua família (BRASIL, 2006).

Ademais, outra consideração importante sobre a década de 1990, segundo Schneider e Niederle (2008), foi o interesse da academia em investigar a agricultura familiar. Vários estudos, livros e pesquisas contribuíram para a afirmação e reconhecimento desse modelo de produção no meio acadêmico.

No contexto da sobrevivência das propriedades agrícolas familiares, os resultados que emergem de vários campos de pesquisa evidenciam estratégias sustentáveis e inovadoras orientadas à continuidade dessas unidades de produção (SUESS-REYES; FUETSCH, 2016). Contudo, Mishra, Hisham, El-Osta e Shaik (2010) afirmam que apesar do importante papel da sucessão, familiar ou não familiar, para a manutenção das propriedades agrícolas, poucos trabalhos são desenvolvidos na área.

\subsection{REPRODUÇÃO SOCIAL E SUCESSÃO NA AGRICULTURA FAMILIAR}

A reprodução social é caracterizada por Almeida (1986) em ciclo curto e ciclo longo. O primeiro, combina trabalho, recursos naturais e o conhecimento tradicional, visando atender o consumo da família. Esse ciclo relaciona-se a perspectiva econômica, que preserva as famílias via trabalho e consumo. Já o ciclo longo, trata efetivamente de como as famílias se perpetuam, sua reprodução no ciclo geracional, sob a lógica de parentesco, que envolve o nascimento, casamento, morte e herança.

$\mathrm{Na}$ concepção de Redin (2015) a reprodução social é um processo constituído por um conjunto de práticas, utilizadas de forma planejada ou não, por um grupo ou sociedade que visa reproduzir sua própria estrutura, um processo amplo vinculado a reprodução cultural, ao habitus e às estratégias, que devem ser pensadas como um todo.

Para Gasson e Errington (1993) citados por Weisheimer (2009), a reprodução social nos estabelecimentos agropecuários familiares depende da formação de novas gerações de agricultores, que envolve um processo composto por três partes:

a) sucessão profissional: que trata da passagem das responsabilidades sobre o negócio e da capacidade de utilização do patrimônio para a próxima geração, bem como a qualificação necessária para a inserção do novo agricultor no mercado;

b) transferência legal da propriedade da terra e dos ativos existentes: resultante do processo de sucessão patrimonial por meio da escolha de um entre os possíveis herdeiros;

c) aposentadoria da atual geração: transferência das responsabilidades e poder para a geração seguinte, em virtude de cessar o trabalho e, consequentemente, o poder da geração atual.

Definido como a transferência gradual do controle da propriedade de uma geração para outra, o processo de sucessão sempre foi significativo na agricultura familiar, porém, com a evolução da realidade rural a ocorrência da sucessão 
assumiu papel crucial para a manutenção dos empreendimentos dessa natureza (HUTSON, 1987).

O processo de sucessão no Brasil até meados de 1970 caracterizava-se pela tradição cultural, que priorizava o acesso à sucessão ao filho mais velho (primogenitura) ou ao mais novo (ultimogenitura ou minorato), deixando parte da família fora do processo, principalmente as filhas. O ofício de agricultor era passado de pai para filho naturalmente, com o desempenho das atividades cotidianas e as políticas públicas estavam distantes da realidade do campo (KISCHENER; KIYOTA; PERONDI, 2015).

Ainda nesse período, Woortmann (1995) elucida que em consequência da diminuição da natalidade, a prática da unigenitura foi facilitada, na qual o filho mais velho compra a parte de terra dos irmãos que irão migrar.

Com a modernização da agricultura, a integração rural-urbana e industrialagrícola, de diferentes valores e sociabilidades, inicia-se uma nova fase no espaço rural marcada por dificuldades em garantir a sucessão familiar (KISCHENER; KIYOTA; PERONDI, 2015).

Para que seja assegurado o prosseguimento do patrimônio familiar, o que é idealizado pelos agricultores, é necessário que seus descendentes tenham como projeto de vida dar continuidade a esse segmento (COSTA, 2011). A transferência bem-sucedida do controle da propriedade é fundamental para manter a unidade de produção viável (HUTSON, 1987).

Considerando os aspectos legais da sucessão patrimonial, Costa, Bezerra e Mendonça (2012) destacam a importância de decidir antecipadamente a forma de transmissão do patrimônio para evitar possíveis conflitos entre os descendentes no momento da partilha.

Nesse contexto, Mello et al. (2003) afirmam que o processo sucessório na agricultura familiar é centrado em torno da figura paterna, que determina o momento e a maneira que serão repassadas as responsabilidades sobre a gestão do estabelecimento para a próxima geração.

Redin (2015) complementa que a sucessão no âmbito da família rural é um campo de conflitos marcado por regras e normas criadas pela família para definir o sucessor, privilegiando os herdeiros com potencial de dar continuidade à função econômica da propriedade. Diversos fatores são considerados para a escolha do sucessor como o gosto pelo trabalho, ausência de conflitos e a dedicação, contudo a redução da família e menor interesse dos filhos em candidatar-se à sucessão tem dificultado esse processo.

Além disso, as condições econômicas e sociais que os agricultores têm a oferecer a seus filhos interferem no momento da sucessão, podendo instigá-la ou rompê-la. O rompimento ocorre quando os projetos individuais dos filhos emergem sobre os dos familiares (MELLO et al., 2003).

A busca por novas atividades ocupacionais faz com que os jovens deixem a propriedade, justificando a afirmação de Abramovay et al. (1998), de que o êxodo rural nas regiões de predomínio da agricultura familiar atinge as populações mais jovens com muito mais ênfase.

\subsection{JUVENTUDE RURAL}

A juventude, segundo Wanderley (2007), é um momento no ciclo da vida caracterizado pela transição entre a infância e a vida adulta. A demarcação dessa etapa da vida é sempre imprecisa, porém é marcada pelo fim dos estudos, início da vida profissional, saída da casa dos pais, constituição de uma família ou simplesmente caracterizada pela faixa etária. 
Waiselfisz (2002) salienta que a definição de juventude pode receber várias conotações de acordo com as diversas áreas do conhecimento. $\mathrm{O}$ autor segue a definição da Organização Mundial de Saúde (OMS), a qual considera que a adolescência e a juventude se diferenciam pelas suas especificidades fisiológicas, psicológicas e sociológicas. O conceito de juventude se resume a uma categoria essencialmente sociológica, que indica o período de preparação dos indivíduos para assumir o papel de adulto na sociedade, compreendendo o contexto familiar e profissional, estendendo-se dos 15 aos 24 anos.

Como retratada por Weisheimer (2009), a juventude é um veículo de ligação entre o passado e o futuro, já que por meio dela a sociedade se altera continuamente. No que diz respeito à atual juventude rural, é possível deduzir que a situação geracional que ela se encontra é diferente daquela de seus pais e avós, que de acordo com Matte et al. (2014), era caracterizada pela sucessão de todos os filhos na atividade agrícola.

Fischer e Burton (2014) aclaram que a socialização com a propriedade na infância é extremamente importante para o desenvolvimento de uma relação de compromisso entre o provável sucessor e o meio em que está inserido. A sucessão não é uma questão de escolha em determinado ponto crítico no ciclo de vida familiar, mas sim um processo de longo prazo de desenvolvimento e preparação do filho para assumir como o sucessor na atividade paterna.

O futuro das unidades de produção familiares está diretamente relacionado com o apego da próxima geração aos negócios familiares e sua intenção em prosseguir com o patrimônio no futuro (SUESS-REYES; FUETSCH, 2016).

No entanto, Costa (2011) relata que grande parte do cenário da agricultura familiar é representada pela juventude rural que sofre com a vulnerabilidade aos processos de mudança do cenário rural, ao estilo de vida e condições de trabalho. Esse cenário é um condicionante que muitas vezes leva essa parcela da população rural a tomar decisões que afetarão a reprodução social das famílias rurais, por meio do processo migratório, responsável por quebrar os mecanismos de hereditariedade.

Apesar de a perspectiva de manter assegurada a sucessão dos estabelecimentos familiares estar associada às características familiares internas (processo ensino-aprendizagem no trabalho familiar e internalização da moral e valores), ela também depende das condições do meio rural, de sua proximidade geográfica, econômica e social com as cidades. Esses fatores podem influenciar na decisão do jovem rural em suceder ou não a atividade paterna (SPANEVELLO, 2008).

\section{METODOLOGIA}

A pesquisa bibliográfica, conforme Gil (2008), é desenvolvida a partir de materiais já elaborados. Apesar da maioria dos trabalhos exigirem pesquisa dessa natureza, existem pesquisas desenvolvidas exclusivamente a partir de fontes bibliográficas, como neste caso. Esse tipo de pesquisa destaca-se por permitir ao investigador acesso à uma vasta série de fenômenos que dificilmente seria possível por meio da coleta direta em campo.

Os artigos que compuseram a amostra deste estudo foram selecionados por meio de busca individual em periódicos classificados no sistema Qualis cadastrados na plataforma Sucupira da Capes (Coordenação de Aperfeiçoamento de Pessoal de Nível Superior), na área de Administração Pública e de Empresas, Ciências Contábeis e Turismo. As buscas ocorreram no período de outubro a dezembro de 2016. Inicialmente foram identificados os periódicos com qualificação A1, A2, B1, B2, B3, B4 e B5, totalizando 1024 periódicos. Desses, foram excluídos 
da amostra os periódicos internacionais e com o escopo não relacionado às áreas abrangentes à administração, que resultou em uma amostra prévia de 334 periódicos.

A pesquisa foi realizada individualmente no portal de cada periódico selecionado, por meio de seus campos de ferramentas de busca. No entanto, 38 periódicos (33 classificados como B4 e 5 como B5 no sistema WebQualis), não apresentaram campo de pesquisa em seu portal, sendo, portanto, excluídos. Dessa forma, os artigos selecionados nesta pesquisa se originaram de 296 periódicos pesquisados.

Para busca nas publicações foram utilizadas cinco palavras-chaves pesquisadas individualmente: sucessão agricultura familiar, sucessão geracional, reprodução social, juventude rural e jovens rurais, que resultaram em 2183 artigos. A princípio adotou-se como critério de exclusão os artigos com o título fora do contexto pesquisado e delimitou-se o período de publicação a partir do ano de 2004, resultando em 64 artigos previamente selecionados.

Realizada a leitura do resumo, foram descartados mais 30 artigos que abordaram como tema central especificamente: reforma agrária, assentamentos, campesinato, educação no campo, PRONAF, contexto geral da agricultura familiar, ruralidade e desenvolvimento, dentre outros. A partir da leitura completa dos artigos restantes foram selecionados 34 artigos que compõem a amostra deste estudo.

\section{RESULTADOS E DISCUSSÕES}

A produção científica brasileira acerca dos temas que envolvem a sucessão na agricultura familiar é ainda pouco explorada. Com base nos dados quantitativos apurados no período de 2004 a 2016 foram selecionados 34 artigos sobre o tema. Tal resultado pode estar relacionado ao fato dos estudos sobre a agricultura familiar serem recentes, visto que a incorporação da expressão agricultura familiar emergiu a partir da década de 1990 como retratado por Schneider e Niederle (2008).

Além do tema central 'agricultura familiar' ter sido evidenciado há menos de três décadas, vale considerar que a preocupação com a dinâmica sucessória emergiu, segundo Matte et al. (2014), com o declínio da população rural brasileira nos últimos anos, marcado pelo fluxo migratório para o meio urbano, principalmente juvenil. Tal fenômeno é resultado do rompimento do compromisso moral de seguir a profissão agrícola presente nas gerações passadas, que aparece cada vez mais como uma escolha, dentre outras possibilidades profissionais (ABRAMOVAY et al., 1998).

Esses fatos justificam a maior concentração de publicações a partir do ano de 2011, sendo 2013 o pico de publicações da área, com 8 artigos, conforme Figura 1 . 
Figura 1 - Produção científica acerca da sucessão na agricultura familiar entre 2004 e 2016

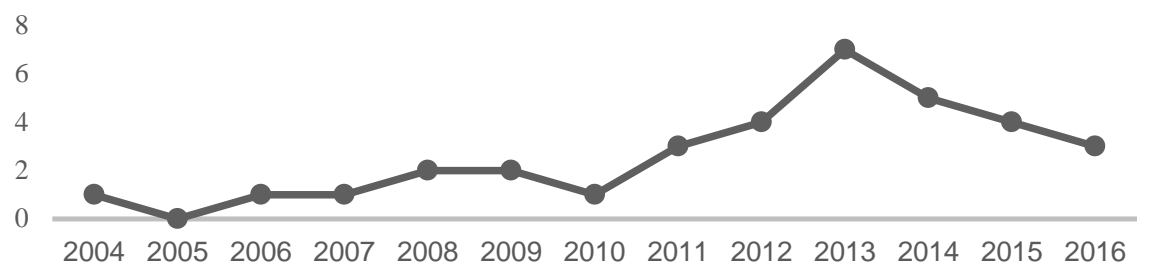

Fonte: Elaborado pelas autoras.

Apenas 7 publicações foram escritas individualmente. Dessa forma, para os 34 artigos selecionados, identificou-se 74 autores. Desses, apenas 5 autores tiveram mais de uma publicação, especificamente 2 artigos cada, todos em parceira com outros autores.

Quanto à instituição de origem, evidenciam-se as universidades localizadas na região sul do país, as quais possuem vínculo com $60,81 \%$ dos autores encontrados na pesquisa. Dentre os estados da região sul, destaca-se o Rio Grande do Sul, já que $48,64 \%$ dos autores possuem vínculo com as instituições dessa localidade, principalmente vinculados à Universidade Federal do Rio Grande do Sul, representada por 20 autores, conforme se apresenta na Figura 2.

Figura 2 - Produção científica em sucessão na agricultura familiar por instituição de origem dos autores

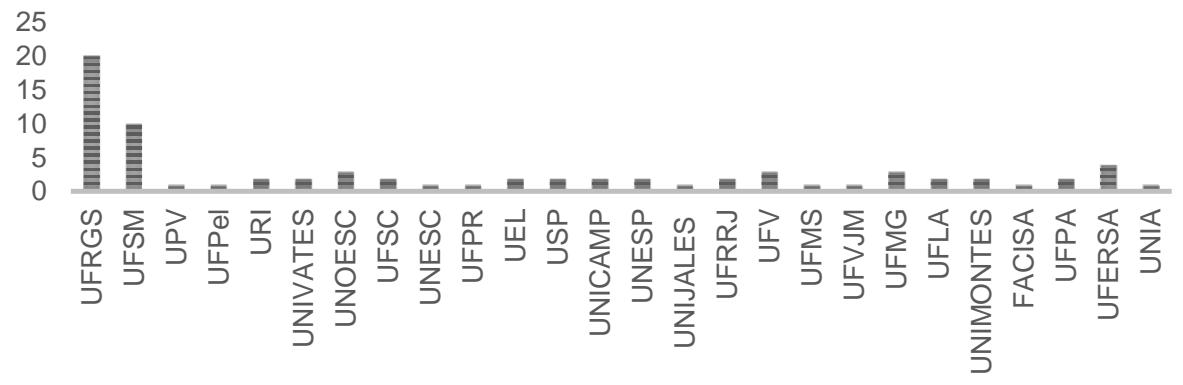

Fonte: Elaborado pelas autoras.

Os periódicos Campo-território: Revista de Geografia Agrária, Extensão Rural e Estudos Sociedade e Agricultura, foram os que se destacaram no quesito quantidade de publicações no período analisado, com 3 artigos cada, conforme apresentado na Figura 3. 
Figura 3 - Produção científica em sucessão da agricultura familiar por periódico

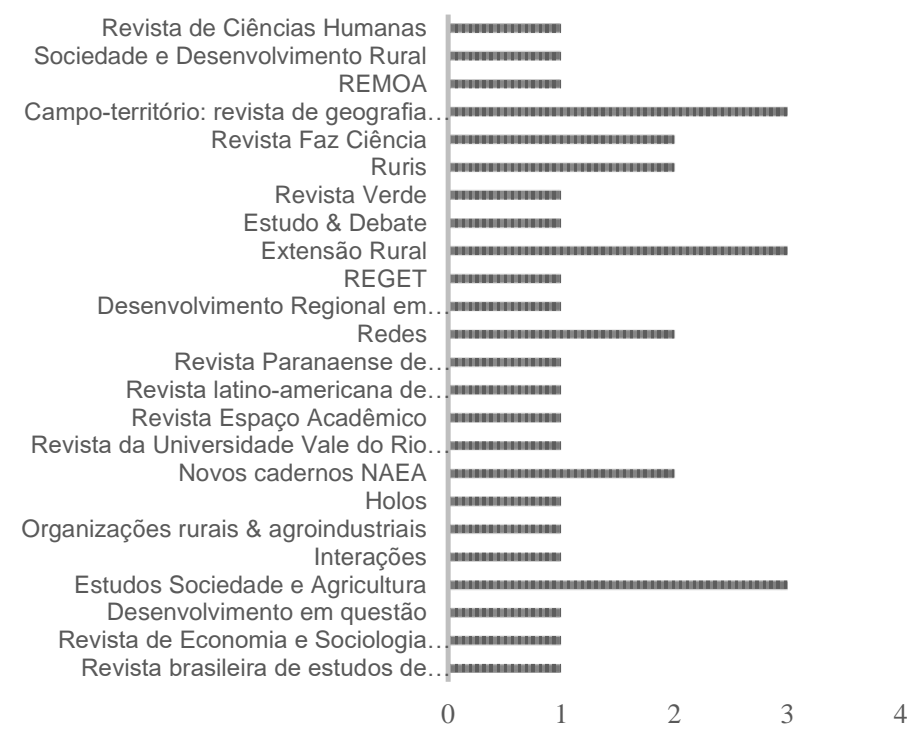

Fonte: Elaborado pelas autoras

Quanto à classificação desses periódicos no sistema Qualis da Capes, a maior concentração de publicações está em revistas classificadas no Qualis B4. Não foram encontrados artigos em periódicos A1 ou A2.

Figura 4 - Publicações por classificação de periódicos web qualis

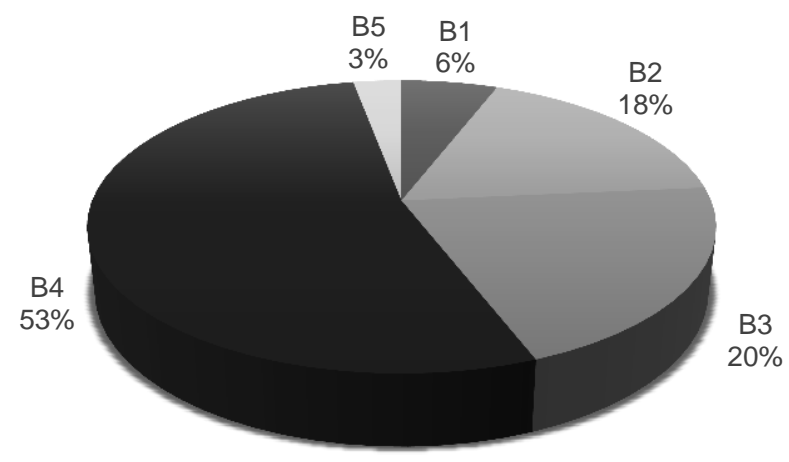

Fonte: Elaborado pelas autoras.

Após a análise de alguns dados quantitativos, os artigos foram classificados em três principais grupos temáticos: sucessão na agricultura familiar, reprodução social e juventude rural. 
4.1 PERFIL METODOLÓGICO DA PRODUÇÃO CIENTÍFICA ACERCA DA SUCESSÃO NA AGRICULTURA FAMILIAR E CONTRIBUIÇÕES PARA O CAMPO DE INVESTIGAÇÃO

Esta seção sistematiza e categoriza os artigos selecionados em quadros segundo seu perfil metodológico e tema central. A classificação metodológica foi embasada no estudo de Tonelli et al. (2003), que utilizaram as indicações de Machado-da-Silva, Cunha e Amboni (1990) Creswell (1998), Eisenhardt (1989), Alvesson e Sköldberg (2000) e Denzin e Lincoln (1994) para fundamentar sua classificação metodológica em:

a) artigos empíricos: não apresentam fundamentação teórica específica, concentram-se em observação e análise dos dados;

b) artigos teóricos-empíricos: apresentam referências teóricas que são confirmadas ou refutadas através da comparação com os dados coletados;

c) artigos teóricos: limitam-se a conceitos, proposições, identificação de variáveis, construção ou reconstrução de modelos, que não envolve teste empírico.

Com relação aos trabalhos que abordaram como tema central a sucessão na agricultura familiar, o Quadro 1 apresenta as principais contribuições dessas pesquisas e seu perfil metodológico. 
Quadro 1 - Artigos identificados no tema central sucessão na agricultura familiar

\begin{tabular}{|c|c|c|}
\hline Pesquisa & Contribuição para o campo de investigação & $\begin{array}{l}\text { Perfil } \\
\text { metodoló } \\
\text { gico }\end{array}$ \\
\hline $\begin{array}{l}\text { Oliveria e } \\
\text { Schneider } \\
\text { (2009) }\end{array}$ & $\begin{array}{l}\text { Indicam que a agroecologia e a diversificação das atividades decorrentes } \\
\text { dela cria novas condições para a manutenção de mais pessoas vivendo e } \\
\text { trabalhando nas propriedades agrícolas, inclusive os jovens. }\end{array}$ & $\begin{array}{l}\text { Teórico- } \\
\text { empírico }\end{array}$ \\
\hline $\begin{array}{l}\text { Chemin } e \\
\text { Alhert (2010) }\end{array}$ & $\begin{array}{l}\text { Analisam o processo de transferência dos bens patrimoniais de } \\
\text { propriedades rurais da agricultura familiar e apresentam ações } \\
\text { preventivas a fim de minimizar os problemas e conflitos que emergem na } \\
\text { sucessão. }\end{array}$ & $\begin{array}{l}\text { Teórico- } \\
\text { empírico }\end{array}$ \\
\hline $\begin{array}{l}\text { Silva e } \\
\text { Wizniewsky } \\
\text { (2011) }\end{array}$ & $\begin{array}{l}\text { Apresentam a pluriatividade, exemplificada pelo artesanato como uma } \\
\text { nova atividade desenvolvida no campo independente do setor agrícola, } \\
\text { como uma estratégia de permanência dos agricultores em suas terras. }\end{array}$ & $\begin{array}{l}\text { Teórico- } \\
\text { empírico }\end{array}$ \\
\hline $\begin{array}{l}\text { Costa e Ralish } \\
\text { (2013) }\end{array}$ & $\begin{array}{l}\text { Identificam que o abandono do campo não é o desejo dos jovens e sim } \\
\text { uma necessidade. A saída do campo muitas vezes é incentivada pelos } \\
\text { pais. A limitação da renda justifica a migração para o meio urbano. }\end{array}$ & $\begin{array}{l}\text { Teórico- } \\
\text { empírico }\end{array}$ \\
\hline $\begin{array}{l}\text { Mendonça, } \\
\text { Ribeiro, } \\
\text { Galizoni e } \\
\text { Augusto } \\
\text { (2013) }\end{array}$ & $\begin{array}{l}\text { Identificam mudanças nos padrões sucessórios de duas gerações de } \\
\text { agricultores, no que tange aos níveis de escolaridade e na dinâmica } \\
\text { tradicional de capacitação de jovens, que influencia nos percursos e } \\
\text { inserção dos migrantes no mercado de trabalho. }\end{array}$ & $\begin{array}{l}\text { Teórico- } \\
\text { empírico }\end{array}$ \\
\hline $\begin{array}{l}\text { Winck, } \\
\text { Pasqua, } \\
\text { Fischer e } \\
\text { Gianezini } \\
(2013)\end{array}$ & $\begin{array}{l}\text { Consideram a busca por uma vida mais estável, com salários fixos, } \\
\text { direitos trabalhistas e com descanso nos finais de semana como fatores } \\
\text { que estimulam o desligamento do jovem ao meio rural. Os jovens que } \\
\text { permanecem na atividade agrícola, geralmente são filhos de produtores } \\
\text { rurais com maior poder aquisitivo. }\end{array}$ & $\begin{array}{l}\text { Teórico- } \\
\text { empírico }\end{array}$ \\
\hline $\begin{array}{l}\text { Franzen } \\
\text { (2014) }\end{array}$ & $\begin{array}{l}\text { Indica que a divisão de pequenos lotes de terras entre os numerosos } \\
\text { filhos, em meados da década de 1950, estimulou a migração para outras } \\
\text { regiôes e incitou a criação de novas perspectivas econômicas para as } \\
\text { gerações vindouras. }\end{array}$ & $\begin{array}{l}\text { Teórico- } \\
\text { empírico }\end{array}$ \\
\hline $\begin{array}{l}\text { Facioni e } \\
\text { Pereira (2015) }\end{array}$ & $\begin{array}{l}\text { Avaliam a importância da renda agrícola e tempo dos assentados no } \\
\text { meio rural no processo sucessório, concluindo que quanto menor a renda } \\
\text { mais se agrava o processo de sucessão e quanto maior o tempo no meio } \\
\text { rural, maior será a escolha pela sucessão }\end{array}$ & $\begin{array}{l}\text { Teórico- } \\
\text { empírico }\end{array}$ \\
\hline $\begin{array}{l}\text { Hillesheim e } \\
\text { Vizzotto } \\
\text { (2015) }\end{array}$ & $\begin{array}{l}\text { Apresentam a pedagogia da alternância como uma possibilidade para o } \\
\text { jovem rural permanecer no campo e desenvolver o meio no qual está } \\
\text { inserido, por meio de alternativas que viabilizem a pequena unidade de } \\
\text { produção familiar a fim de criar a possibilidade de sucessão no campo. }\end{array}$ & $\begin{array}{l}\text { Teórico- } \\
\text { empírico }\end{array}$ \\
\hline $\begin{array}{l}\text { Matte, } \\
\text { Spanevello e } \\
\text { Andreatta. } \\
\text { (2015) }\end{array}$ & $\begin{array}{l}\text { Evidenciam o afastamento dos filhos das atividades da propriedade e } \\
\text { ausência desses na tomada de decisões e na administração dos } \\
\text { negócios como fatores que não os estimulam a ver a vida no meio rural } \\
\text { como viável e sustentável. }\end{array}$ & $\begin{array}{l}\text { Teórico- } \\
\text { empírico }\end{array}$ \\
\hline $\begin{array}{l}\text { Pereira, Reis } \\
\text { e Oliveira } \\
\text { (2012) }\end{array}$ & $\begin{array}{l}\text { Discorrem sobre a igualdade de gênero, ressaltando que embora as } \\
\text { mulheres passem a receber parcela de terra como herança, essa área se } \\
\text { mantem sob domínio do marido. }\end{array}$ & Teórico \\
\hline Savian (2014) & $\begin{array}{l}\text { Considera a renda como fator de grande influência na decisão de ficar ou } \\
\text { partir. Apesar da relevância desse fator, a hierarquia doméstica, } \\
\text { valorização do urbano, questões de gênero e outros fatores contribuem } \\
\text { para a tomada de decisão. }\end{array}$ & Teórico \\
\hline
\end{tabular}

Fonte: Elaborado pelas autoras. 
O perfil metodológico teórico-empírico prevalece nesse grupo, representado por $83,33 \%$ das pesquisas, os demais estudos caracterizam-se como teóricos. Apesar de todas as pesquisas denotadas no quadro apresentarem resultados importantes para estudo do tema, serão discutidos alguns resultados de estudos que contribuem para o entendimento da temática no contexto geral. Dentre as contribuições dos estudos, o fator renda é destacado como um dos principais motivos que comprometem a sucessão da atividade agrícola familiar.

Em sua pesquisa, Costa e Ralish (2013) levantaram a hipótese de que o desejo dos jovens em abandonar o assentamento Florestan Fernandes no Município de Florestópolis - PR estava relacionado à atração pela vida urbana e suas comodidades. No entanto, a hipótese não foi confirmada, os pesquisadores comprovaram que a limitação da renda obtida na propriedade provoca o abandono do campo em busca da independência financeira, restando uma população rural envelhecida. Dessa forma, a saída do campo não é vista como um desejo, e sim, uma necessidade.

O acesso à educação no campo é dificultado em virtude da falta de oportunidade ou da necessidade de locomoção para as cidades, que muitas vezes se torna inviável devido às obrigações com o trabalho na propriedade (HILLESHEIM; VIZZOTTO, 2015).

Considerando essa realidade do acesso à educação no campo, Hillesheim e Vizzotto (2015) estudaram a contribuição da pedagogia da alternância, uma proposta de ensino em que os jovens passam um período de internato na escola e outro na propriedade familiar, para a sucessão da agricultura familiar. O objetivo dessa modalidade de ensino, além da formação integral, é mostrar oportunidades para que o jovem desenvolva o conhecimento adquirido na escola em sua propriedade, visando a melhoraria da renda e qualidade de vida da família.

A qualificação, além de aprimorar o desenvolvimento das atividades já realizadas na propriedade, vislumbra a oportunidade de empreender novos negócios, promovendo a diversificação na agricultura familiar ou a pluriatividade, apontadas por Oliveira e Schneider (2009) e Silva e Wizniewsky (2011) como importantes estratégias de aumento de renda que motivam a manutenção das famílias no campo.

Outro fator importante no contexto da sucessão familiar é discorrido no estudo de Chemin e Alhert (2010) que tratam dos aspectos legais da transmissão do patrimônio, o que geralmente ocorre quando o titular falece. Os autores evidenciam a importância de a família preocupar-se desde cedo com o processo sucessório para que os negócios e a vida no campo permaneçam, apresentando possibilidades legais adequadas enquanto os atuais proprietários estão vivos, como a doação de parte da propriedade, usufruto ou até mesmo parcerias com os filhos que continuam na propriedade para que disponham de recurso para compra da parte dos demais herdeiros.

No contexto geral, os estudos analisados evidenciaram: limitação da renda, falta de estrutura no meio rural, limitação de políticas públicas, participação tardia dos jovens nas decisões que envolvem a gestão da propriedade, dificuldade no acesso à educação devido à distância dos centros de ensino e a desigualdade de gênero, como fatores que desestimulam a permanência dos jovens no meio rural.

Por outro lado, as pesquisas também evidenciaram os fatores que sustentam a sucessão das propriedades agrícolas familiares, como o acesso à educação por meio da pedagogia da alternância, investimento na diversificação de atividades produtivas e pluriatividade, e a preocupação prévia sobre o destino da propriedade, no que tange ao repasse das responsabilidades e transferência dos bens. 
A sucessão compreende também a agricultura familiar enquanto categoria social, considerando seu modo de vida específico. Alguns autores associam o termo sucessão à reprodução social no campo. O Quadro 2 apresenta os estudos identificados nessa temática.

\begin{tabular}{|c|c|c|}
\hline Autores & Contribuição para o campo de investigação & $\begin{array}{l}\text { Perfil } \\
\text { metodológico }\end{array}$ \\
\hline $\begin{array}{l}\text { Lacerda e } \\
\text { Marques } \\
(2008)\end{array}$ & $\begin{array}{l}\text { Indicam a pluriatividade como base para a reprodução } \\
\text { econômica e, ao mesmo tempo, familiar, fundada na } \\
\text { preocupação ambiental e oferta de alimentos saudáveis. A } \\
\text { partir da multifuncionalidade da agricultura, articula diferentes } \\
\text { oportunidades que emergem das novas configurações do } \\
\text { espaço rural. }\end{array}$ & Teórico-empírico \\
\hline $\begin{array}{l}\text { Pelegrini e } \\
\text { Gazolla } \\
(2009)\end{array}$ & $\begin{array}{l}\text { Apontam a agro industrialização familiar como uma estratégia } \\
\text { de reprodução social e de desenvolvimento rural, responsável } \\
\text { pela fixação das famílias no campo, pela diversificação de } \\
\text { atividades produtivas nas propriedades rurais e pela geração de } \\
\text { renda nas famílias. }\end{array}$ & Teórico-empírico \\
\hline $\begin{array}{l}\text { Corona } \\
\text { (2011) }\end{array}$ & $\begin{array}{l}\text { Apresenta estratégias concretas que permitem a reprodução da } \\
\text { agricultura familiar, tais como a incorporação das novas } \\
\text { ruralidades, representada principalmente pela pluriatividade } \\
\text { como o turismo rural e a conversão para a produção "mais } \\
\text { natural". }\end{array}$ & Teórico-empírico \\
\hline Redin (2011) & $\begin{array}{l}\text { Discorre sobre as estratégias de reprodução social em duas } \\
\text { categorias: amplas e restritas. As estratégias amplas referem- } \\
\text { se a produção não agrícola, contextualizando a pluriatividade e } \\
\text { multifuncionalidade na agricultura. Já as estratégias restritas } \\
\text { envolvem as famílias agricultoras que sempre se dedicaram a } \\
\text { um único cultivo. }\end{array}$ & Teórico-empírico \\
\hline $\begin{array}{l}\text { Saron e } \\
\text { Hespanhol } \\
(2012)\end{array}$ & $\begin{array}{l}\text { Contextualizam a importância do perfil cada vez mais } \\
\text { empresarial. Esse perfil empreendedor tem maior capacidade } \\
\text { de oferecer condições para a sucessão na unidade produtiva } \\
\text { familiar. Apresenta a importância da união dos agricultores em } \\
\text { torno das organizações coletivas e desenvolvimento de } \\
\text { atividades diversas na propriedade para fortalecimento da } \\
\text { agricultura familiar. }\end{array}$ & Teórico-empírico \\
\hline Costa (2013) & $\begin{array}{l}\text { Apresenta o celibato rural masculino no sul do Brasil, a figura } \\
\text { do "solteirão" como consequência para a reprodução social no } \\
\text { campo e por conseguinte a sucessão dos estabelecimentos } \\
\text { rurais, principalmente os familiares. }\end{array}$ & Teórico-empírico \\
\hline $\begin{array}{l}\text { Silva, Netto e } \\
\text { Silva (2013) }\end{array}$ & $\begin{array}{l}\text { Apresentam a pluriatividade, diversificação, com destaque para } \\
\text { a agricultura agroecológica como estratégias para garantir a } \\
\text { reprodução social em meio ao novo rural marcado pela queda } \\
\text { de renda e emprego agrícola, especialização produtiva e novos } \\
\text { fenômenos demográficos, como a masculinização, } \\
\text { envelhecimento e êxodo seletivo. }\end{array}$ & Teórico-empírico \\
\hline $\begin{array}{l}\text { Paixão, } \\
\text { Mera, Diverio } \\
(2015)\end{array}$ & $\begin{array}{l}\text { Evidenciam a diversificação e pluriatividade, destacando a } \\
\text { atividade leiteira como estratégia para o fortalecimento da } \\
\text { agricultura familiar, visto que em pequenas áreas consegue-se } \\
\text { produzir escalas competitivas que viabilizam a atividade e a } \\
\text { permanência dos produtores no meio rural. }\end{array}$ & Teórico-empírico \\
\hline
\end{tabular}

Fonte: Elaborado pelas autoras.

Quanto ao perfil metodológico todas as pesquisas foram fundamentadas na metodologia teórica-empírica. No que tange às contribuições para o campo de investigação, percebe-se forte influência da pluriatividade e diversificação da produção como estratégia de reprodução social, visto que foram consenso nos estudos elencados. 
A pluriatividade apresenta um novo conceito para a unidade de produção e reprodução familiar, no qual atividades não agrícolas integram a economia das propriedades. Essa forma de organização do trabalho ocorre quando pelo menos um indivíduo de uma família residente no meio rural passa a exercer um conjunto de atividades econômicas e produtivas variado, não necessariamente relacionadas à agricultura ou cultivo da terra (SCHNEIDER, 2003).

Assim, como na análise dos artigos do Quadro 1, apesar de todos os artigos selecionados apresentarem contribuições para o campo de investigação, são discorridos os artigos com resultados ou área de pesquisa considerados mais específicos, a fim de exemplificar as diversas possibilidades de pesquisa que envolvem a área de estudo.

Ao investigar uma comunidade na região metropolitana de Curitiba, Corona (2011) observou que as estratégias de trabalho adotadas pelos agricultores foram incrementadas a partir das atividades tradicionais desempenhadas pelos colonizadores. Os produtos artesanais provenientes da uva movimentam o turismo rural que sustenta a economia da comunidade garantindo a reprodução social.

Paixão, Mera e Diverio (2015) avaliaram a possibilidade de diversificação e manutenção de atividades pluriativas em uma região com baixa disponibilidade de área para produção, difícil acesso ao crédito, aos recursos financeiros e desenvolvimento tecnológico, o Alto Jacuí - RS. Nessa localidade, as atividades desenvolvidas estão concentradas na triticultura, sojicultora, produção de milho e de leite e comercialização de excedentes. Contudo, a produção leiteira favorece a permanência da população no campo, pela viabilidade de desenvolver a atividade em pequenas áreas.

Ainda no estado do Rio Grande do Sul, Pelegrini e Gazolla (2009) evidenciam a agroindústria familiar como uma importante estratégia de reprodução social, do ponto de vista econômico, social e produtivo, muitas vezes gerando maior renda do que as demais atividades agropecuárias, como o cultivo de grãos. Dessa forma, é apontada como uma estratégia de desenvolvimento sustentável a médio e longo prazo para as unidades produtivas familiares.

Percebe-se o extenso rol de atividades que podem ser exploradas no campo. Considerando essa realidade, os resultados da pesquisa de Saron e Hespanhol (2012) apontam a presença de um agricultor com perfil cada vez mais empresarial, com condições de gerir essas atividades e permanecer no campo, dispondo de melhores condições para proceder a sucessão da unidade produtiva familiar.

Como agravante à reprodução social, o estudo de Silva, Netto e Silva (2013) enfatiza os fenômenos demográficos da masculinizacão e envelhecimento da população rural em virtude do êxodo seletivo, o qual tem remetido às cidades, principalmente jovens do sexo feminino, em busca de oportunidades de emprego não encontradas no campo, que geralmente estão relacionadas aos cuidados da casa, filhos e horta.

Esses acontecimentos também foram estudados por Costa (2013) que abordou a ocorrência do celibato no sul do Brasil, fenômeno que resulta principalmente da intensificação da migração juvenil feminina para a cidade, contribuindo para a masculinizacão no campo e, consequentemente, gerando dificuldades em firmar laços matrimonias, comprometendo a reprodução social.

É consenso nas pesquisas a influência da pluriatividade e diversificação de atividades agrícolas para assegurar a reprodução da agricultura familiar, enquanto categoria social. As pesquisas apontam diversas atividades como oportunidades de investimento nas propriedades rurais, tanto para propriedades com menor extensão de área de terra, que podem investir na agroecologia através de hortaliças, pecuária 
e até mesmo agroindústrias, bem como para propriedades maiores, com melhores oportunidades para o cultivo de grãos.

Além das estratégias que contribuem para a reprodução social, também é enfatizado o fator que compromete a reprodução: a migração juvenil, em maior escala pelo sexo feminino, impactando na masculinização no campo. Esse fenômeno compromete a constituição de laços matrimoniais e a consequente reprodução da categoria social, já que o casamento geralmente ocorre com jovens com vínculo no meio rural.

Os fenômenos que englobam a classe jovem da população rural são de suma importância nos estudos relacionados à sucessão dos estabelecimentos rurais familiares, portanto, o Quadro 3 reúne os artigos que abrangem essa temática.

Quadro 3 - Artigos identificados no tema central juventude rural

\begin{tabular}{|c|c|c|}
\hline Autores & Contribuição para o campo de investigação & $\begin{array}{l}\text { Perfil } \\
\text { metodológico }\end{array}$ \\
\hline $\begin{array}{l}\text { Ferrari et al. } \\
(2004)\end{array}$ & $\begin{array}{l}\text { Ressaltam que os jovens de } 13 \text { a } 18 \text { anos, principalmente as } \\
\text { moças, não manifestam interesse em seguir a atividade agrícola. } \\
\text { Já os jovens acima de } 25 \text { anos que ainda permanecem morando } \\
\text { na propriedade são os candidatos naturais à sucessão no } \\
\text { estabelecimento do pai }\end{array}$ & Teórico-empírico \\
\hline $\begin{array}{l}\text { Segundo e } \\
\text { Silva et al. } \\
(2006)\end{array}$ & $\begin{array}{l}\text { Avaliam as condições de vida dos jovens no campo, um lugar } \\
\text { bom para se viver, mas não oferece condições para o jovem } \\
\text { permanecer morando nele. A maioria dos jovens tem intenção de } \\
\text { sair do campo, quanto aos pais, sobressai o desejo que as filhas } \\
\text { migrem em busca de novas oportunidades. }\end{array}$ & Teórico-empírico \\
\hline $\begin{array}{l}\text { Martins } \\
(2007)\end{array}$ & $\begin{array}{l}\text { Mostra a importância da criação de políticas públicas que } \\
\text { atendam às especificidades dos jovens rurais, bem como a } \\
\text { participação efetiva das diversas organizações do campo. }\end{array}$ & Teórico-empírico \\
\hline $\begin{array}{l}\text { Pereira } \\
\text { (2008) }\end{array}$ & $\begin{array}{l}\text { Evidencia o desejo dos jovens em desvincular-se da imagem } \\
\text { tradicional do agricultor familiar. Aqueles que manifestam } \\
\text { interesse em permanecer no campo utilizam a categoria } \\
\text { administrador(a) para se referir ao seu futuro. }\end{array}$ & Teórico-empírico \\
\hline $\begin{array}{l}\text { Spanevello } \\
\text { et al. (2011) }\end{array}$ & $\begin{array}{l}\text { Apontam a recusa dos filhos em suceder a profissão devido às } \\
\text { dificuldades do trabalho no rural, busca de lazer, contato com o } \\
\text { urbano, redução do número de filhos por família, falta de abertura } \\
\text { dos pais para o desenvolvimento das atividades na propriedade } \\
\text { ou oportunidade de empreender novas atividades e busca da } \\
\text { autonomia financeira. }\end{array}$ & Teórico-empírico \\
\hline $\begin{array}{l}\text { Martins e } \\
\text { Futemma } \\
(2012)\end{array}$ & $\begin{array}{l}\text { Assinalam o turismo rural como alternativa para melhoria de } \\
\text { renda e baixo impacto ambiental que favorece a fixação dos } \\
\text { jovens no espaço rural. }\end{array}$ & Teórico-empírico \\
\hline $\begin{array}{l}\text { Mera e Netto } \\
(2012)\end{array}$ & $\begin{array}{l}\text { Justificam a migração para a cidade como expectativa dos pais } \\
\text { em oferecer uma qualidade de vida melhor aos seus filhos, no } \\
\text { quesito profissão. Com a saída dos jovens intensifica-se o } \\
\text { arrendamento das terras a terceiros, devido a insuficiente mão de } \\
\text { obra familiar para desempenho das atividades. }\end{array}$ & Teórico-empírico \\
\hline $\begin{array}{l}\text { Alves e Mota } \\
(2013)\end{array}$ & $\begin{array}{l}\text { Indicam o fator renda como determinante para que os jovens } \\
\text { permaneçam na atividade agrícola, evidenciando a busca de } \\
\text { novas alternativas de renda por meio do assalariamento, até } \\
\text { mesmo na agricultura, mas em propriedades vizinhas. Contudo } \\
\text { outros jovens anseiam encontrar fora da atividade agrícola seus } \\
\text { projetos de vida. }\end{array}$ & Teórico-empírico \\
\hline
\end{tabular}

(Continua) 


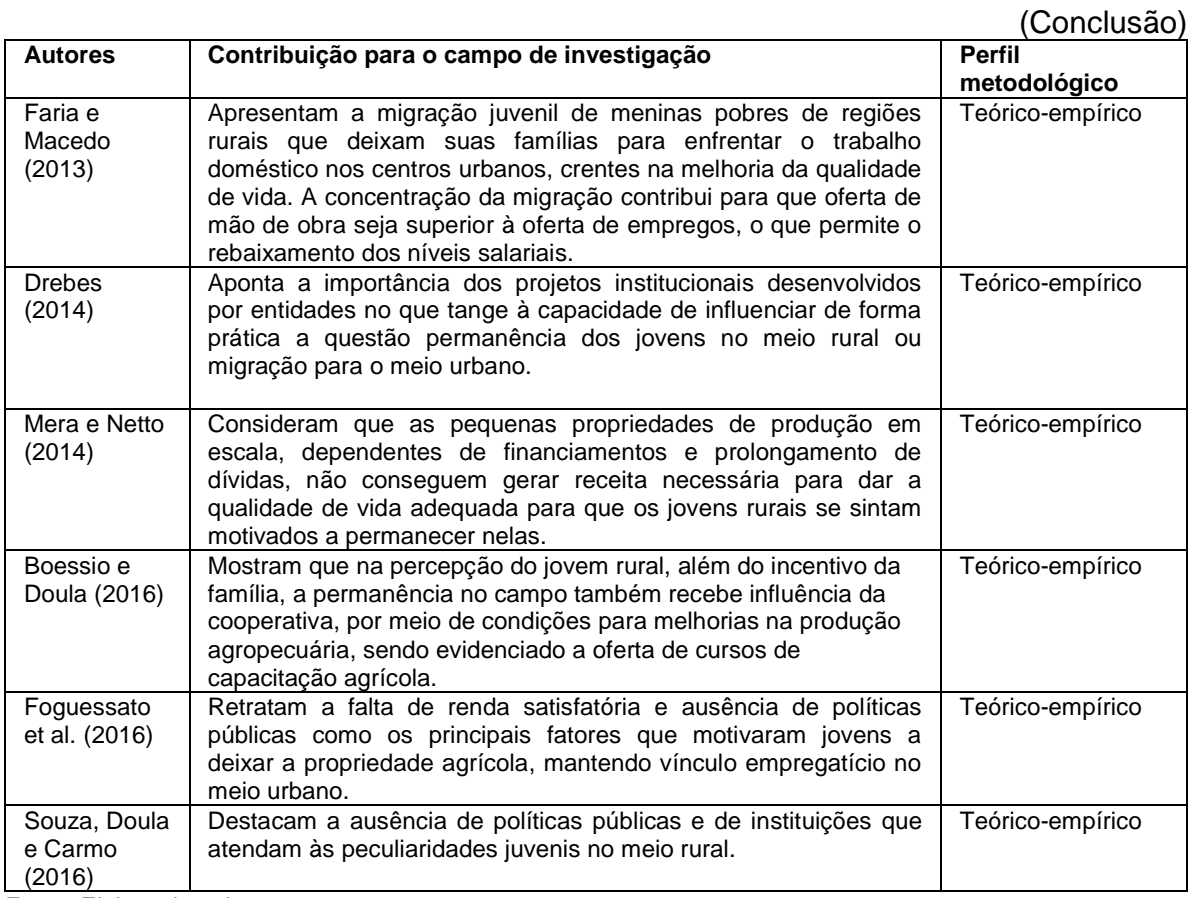

Fonte: Elaborado pelas autoras.

Assim como o grupo anterior, os estudos relacionados à juventude rural foram construídos a partir da metodologia teórica-empírica. A migração juvenil é motivada por diversos fatores, além da questão da renda insatisfatória como já apresentado em outros grupos de análise. Dentre eles, a ausência de políticas públicas para incentivar a permanência juvenil no campo é notória.

A pesquisa de Souza, Doula e Carmo (2016) aponta a percepção negativa dos jovens rurais da Zona da Mata Mineira quanto à ausência de políticas públicas e instituições que atendam suas particularidades juvenis no meio rural, como o acesso à formação e à capacitação profissional, por meio da interiorização do ensino superior.

Ainda no que tange à capacitação dos jovens, os estudos de Boessio e Doula (2016) e Drebes (2014) apresentam a influência das cooperativas e projetos institucionais em viabilizar a permanência do jovem no campo, por meio de programas que incentivem e promovam sua capacitação.

Além dos fatores externos à propriedade, a recusa em suceder a profissão paterna também está relacionada à falta de abertura dos pais para o desenvolvimento das atividades, conforme apontado no estudo de Spanevello et al. (2011), realizado na região central do Rio Grande do Sul. Tal posicionamento muitas vezes está relacionado à crença paterna de que a educação formal adquirida pelos filhos é diferente das práticas tradicionais, gerando um espaço de conflito.

Esse posicionamento empreendedor, muitas vezes não incentivado pelos pais, é tratado no estudo de Pereira (2008), que apresenta novas perspectivas da juventude rural, atribuindo uma nova identidade ao agricultor familiar, afastando-o da imagem de um rural atrasado, sem acesso à educação e tecnologia. Esses jovens 
buscam incorporar novos valores inclusive no âmbito da organização da produção familiar.

Quanto ao êxodo rural feminino, o estudo de Segundo e Silva et al. (2006) justifica a intensificação desse fenômeno devido ao desejo dos pais para que suas filhas busquem novas oportunidades de trabalho e melhoria de qualidade de vida na cidade.

Ainda conforme Segundo e Silva et al. (2006), na perspectiva dos jovens, o campo representa um bom lugar para se viver, no entanto, não oferece estrutura para permanecer morando nele. Tais fragilidades são apontadas por Spanevello et al. (2011) no que tange às estruturas comunitárias como escolas, igrejas, ginásios de esporte, entre outros, relacionando a falta de investimento com a diminuição da população local.

Os estudos analisados nos três grupos temáticos permitiram identificar os principais fatores que contribuem para a manutenção do jovem no campo sucedendo a profissão paterna bem como os que motivam a migração da população jovem rural para o meio urbano em busca de uma nova perspectiva de vida. O Quadro 4 apresenta os fatores que favorecem a sucessão na agricultura familiar ou a migração para o meio urbano.

Quadro 4 - Fatores que favorecem a sucessão na agricultura familiar ou a migração para o meio urbano

\begin{tabular}{|l|l|}
\hline $\begin{array}{l}\text { Fatores que favorecem } \\
\text { a sucessão na }\end{array}$ & $\begin{array}{l}\text { Diversificação de atividades desenvolvidas na propriedade; Pluriatividade } \\
\text { (artesanatos, agro industrialização, agroecologia, turismo rural); }\end{array}$ \\
Capacitação profissional; Pedagogia da alternância; Incentivo da família; \\
Transmissão gradativa das responsabilidades e do patrimônio; Perfil \\
empreendedor; Envolvimento das cooperativas com os jovens rurais; \\
Qualidade de vida no campo
\end{tabular}

Fonte: Elaborado pelas autoras.

Apesar de a juventude rural representar o futuro das unidades de produção rural familiar, no contexto geral os estudos apontam limitações presentes no meio rural que incentivam a migração juvenil para as cidades. Dentre elas, as condições econômicas oferecidas pelos agricultores aos seus filhos, fruto das atividades desenvolvidas na propriedade tem grande peso na decisão de permanecer no campo.

A limitação da renda gerada na propriedade, de acordo com os estudos analisados, figura o principal fator que instiga os jovens a não suceder a atividade paterna, justificando a migração como uma necessidade e não como um desejo. Tal decisão está relacionada à busca por sua autonomia financeira por meio do trabalho assalariado na cidade. Além disso, a ausência de salário fixo no campo também contribui para a migração.

A renda insatisfatória apontada nesses estudos pode ser resultado do insuficiente incentivo governamental e das instituições em que a classe agricultora está ligada. Esses fatores também são evidenciados nos estudos analisados, os 
quais apontam a ausência de políticas públicas direcionadas aos jovens e distanciamento das cooperativas dos possíveis sucessores como determinantes na decisão de deixar o campo.

A falta de autonomia dos jovens em relação ao desempenho das atividades também estimula a busca por novas oportunidades de trabalho. A transferência tardia de responsabilidades no que tange à gestão da propriedade mantém o jovem restrito às ordens dos pais, impossibilitando a busca por novas oportunidades de investimento ou até mesmo novas formas de desenvolver o trabalho.

Assim como as dificuldades do meio rural são percebidas pelos jovens, muitos pais também não consideram a agricultura como uma oportunidade de vida para seus filhos. Nesses casos, é comum o incentivo paterno para a saída dos filhos da propriedade, instigando-os a estudar a fim de conquistar um espaço no mercado de trabalho urbano, tal desejo ocorre principalmente em relação às filhas, que no contexto geral manifestam menor interesse em permanecer no campo do que os jovens do sexo masculino.

O contato com o meio urbano, geralmente para estudar, apresenta ao jovem uma nova realidade, com mais opções de lazer, vislumbrando a melhoria de qualidade de vida. A dificuldade de locomoção para estudar na cidade, bem como a dedicação em tempo integral à propriedade, sem férias ou descanso nos feriados, também contribuem para a busca pelo modo de vida urbano.

Por outro lado, os jovens que desejam prosseguir na propriedade, buscam desmistificar a imagem do agricultor a um rural atrasado. Esses jovens buscam qualificação profissional visando oportunidades de investimento no campo. Nesse quesito a pedagogia da alternância destaca-se por sua contribuição na formação do jovem empreendedor rural.

A ação empreendedora no campo tem grande responsabilidade em oferecer condições para a manutenção da classe dos agricultores familiares, tal característica reflete na diversificação da produção e pluriatividade que contribuem para o incremento da renda.

Além disso, a transmissão gradativa das responsabilidades gerenciais oportuniza aos jovens maior envolvimento com o trabalho, fortalecendo seu vínculo com a propriedade. Essa iniciativa dos pais antes de sua aposentadoria é entendida como um incentivo para que os jovens permaneçam na atividade agrícola.

O envolvimento das cooperativas com os jovens também contribui para a formação de empreendedores rurais e prospecção de novos cooperados. A participação efetiva dos jovens nessas entidades motiva seu envolvimento com as atividades da propriedade e desenvolve suas responsabilidades sobre ela.

Por fim, destaca-se que apesar da dedicação integral ao trabalho a qualidade de vida no campo, no quesito moradia, é evidenciada como um fator positivo para a permanência no campo.

\section{CONSIDERAÇÕES FINAIS}

Os resultados desta pesquisa evidenciam a restrição da produção acadêmica publicada em periódicos do sistema Qualis da área de Administração Pública e de Empresas, Ciências Contábeis e Turismo no campo da sucessão da agricultura familiar no período de 2004 a 2016. É importante considerar que apenas o período analisado não permite que se considere como absolutos os resultados apresentados sobre os aspectos que envolvem a sucessão na agricultura familiar.

Para Silva et al. (2006) existem poucas pessoas dedicadas a estudar a realidade dos jovens rurais. Essa limitação relaciona-se principalmente por ser um tema relativamente novo. Tal consideração justifica a maior concentração de 
pesquisas publicadas nos últimos seis anos, representando $76 \%$ da amostra pesquisada, sendo o pico o ano de 2013, com sete artigos.

A pesquisa sobre a sucessão na agricultura familiar é centralizada na região sul do país, especialmente no estado do Rio Grande do Sul, prevalecendo as pesquisas teórico-empírica, sobressaindo-se os estudos de caso.

No quesito quantidade de publicações por autores, não foram identificados autores com mais de duas publicações no período analisado, fato que também pode ser justificado pelo recente interesse em realizar estudos na área.

No contexto geral, constatou-se que as pesquisas abordaram a questão da renda como principal limitador da permanência do jovem no campo, além da fragilidade da infraestrutura do campo, dificuldade no acesso à educação, ausência de políticas públicas que incentivem a fixação do jovem no meio rural, desigualdade de gênero e visão negativa dos pais quanto ao futuro dos filhos na propriedade. Ademais, a demora dos pais no repasse das responsabilidades no que tange à gestão da propriedade e transferência dos bens aos possíveis sucessores também é um fator que os instiga a buscar oportunidades de trabalho fora da unidade de produção familiar.

Como fatores que contribuem para a sucessão na agricultura familiar percebe-se forte influência da pluriatividade e diversificação da produção, sendo apontada a agroecologia e a agroindústria como atividades que agregam valor à produção propiciando o aumento da renda, principalmente em propriedades com menor extensão de área produtiva. Tais iniciativas são percebidas pelos jovens que buscam qualificação profissional para empregar o conhecimento na propriedade, com destaque à pedagogia da alternância. O incentivo familiar, participação em atividades promovidas pelas cooperativas e perfil empreendedor dos jovens também são fatores positivos que motivam a permanência no campo.

Esta investigação permitiu reunir os resultados no campo investigativo da sucessão da agricultura familiar e dessa forma possibilitou maior compreensão sobre a temática. Ficou evidente a importância da realização de estudos na área a fim de contribuir para a continuidade desse modelo de produção altamente relevante para o desenvolvimento da economia regional e nacional, principalmente em regiões de predominância da agricultura familiar.

\section{REFERÊNCIAS}

ABRAMOVAY, R.; SILVESTRO, M. L.; CORTINA, N.; BALDISSERA, I. T.; FERRARI, D. L.; TESTA, V. M. Juventude e agricultura familiar: desafios dos novos padrões. Brasília: Unesco, 1998.

ALMEIDA, M. W. B. Redescobrindo a família rural. Revista Brasileira de Ciências Sociais, v. 1, n. 1, p. 66-83, 1986.

ALVES, K. S.; MOTA, D. M. Trabalho familiar ou assalariamento? Dilema de jovens em comunidades rurais. Novos Cadernos NAEA, v. 16, n. 1, p. 163-180, 2013.

BOESSIO, A. T.; DOULA, S. M. Jovens rurais e influências institucionais para a permanência no campo: um estudo de caso em uma cooperativa agropecuária do Triângulo Mineiro. Interações, v. 17, n. 3, p. 370-383, 2016.

BRASIL. Economia e emprego. Agricultura familiar produz $70 \%$ dos alimentos consumidos por brasileiro. 2015. Acessado em: 14/01/2018. Disponível em: 
http://www.brasil.gov.br/economia-e-emprego/2015/07/agricultura-familiar-produz-70dos-alimentos-consumidos-por-brasileiro.

BRASIL. Lei $\mathbf{n}^{\circ}$ 11.326, de 24 de julho de 2006. Estabelece as diretrizes para a formulação da Política Nacional da Agricultura Familiar e Empreendimentos Familiares Rurais. Diário Oficial da União, Brasília, DF. 2006. Disponível em: <http://www.planalto.gov.br/ccivil_03/_ato2004-2006/2006/lei/l11326.htm>. Acesso em: 14 jan. 2018.

BRUMER, A. A problemática dos jovens rurais na pós-modernidade. In: VII Congreso Latinoamericano de Sociología Rural, 2006, Quito (Equador). Anais...

CHEMIN, B. F.; AHLERT, L. A sucessão patrimonial na agricultura familiar. Estudo \& Debate, v. 17, n. 1, p. 49-74, 2010.

CORONA, H. M. P. A agricultura familiar na RMC: um olhar sobre a relação ambiente e sociedade a partir da comunidade de Mergulhão. Redes, v. 16, n. 3, p. 138-156, 2011.

COSTA, C. Contornos do celibato no espaço rural: solteirões do sul do Brasil. Extensão Rural, Santa Maria, v. 21, n. 3, p. 22-51, 2013. Disponível em: https://periodicos.ufsm.br/extensaorural/article/view/7312.

COSTA, F. L. M.; RALISCH, R. A juventude rural do Assentamento Florestan Fernandes no Município de Florestópolis (PR). Revista de Economia e Sociologia Rural, v. 51, n. 3, p. 415-432, 2013.

COSTA, M. R. C. O futuro entre o rural e o urbano. Um estudo de caso sobre a juventude rural no município de Morro Redondo-RS. 2011. 117f. Tese (Doutorado em Sistemas de Produção Agrícola Familiar) - Programa de PósGraduação em Sistemas de Produção Agrícola Familiar, Faculdade de Agronomia Eliseu Maciel da Universidade Federal de Pelotas.

COSTA, M. R. C.; BeZERRA, A. J. A.; MENDONÇA, H. A. F. Expectativas de sucessão hereditária nas unidades de produção familiares. Um olhar sobre o município de morro Redondo, RS. ACTA Geográfica, v. 6, n. 12, p. 139-154, 2012.

DREBES, L. M. Projeto de juventude rural, campo de possibilidades e migração: um estudo documental do Centro de Desenvolvimento do Jovem Rural (CEDEJOR). REMOA, v. 13, n. 5, p. 4087-4098, 2014.

FACIONI, D.; PEREIRA, M. W. G. Análise dos determinantes da sucessão em assentamento rural no estado de Mato Grosso do Sul. Organizações Rurais \& Agroindustriais, v. 17, n. 1, p. 119-136, 2015.

FARIA, G. J. A.; MACEDO, L. A. M. Meninas migrantes: a migração infanto-juvenil rural e sua inserção no trabalho doméstico urbano. Revista UNIOESTE, v. 15, n. 22, p. 103-115, 2013.

FERRARI, D. L.; ABRAMOVAY, R.; SILVESTRO, M. L.; MELLO, M. A.; TESTA, V. M. Dilemas e estratégias dos jovens rurais: ficar ou partir? Estudos Sociedade e Agricultura, v. 12, n. 2, p. 237-271, 2004. 
FISCHER, H.; BURTON, R. J. F. Understanding Farm Succession as Socially Constructed Endogenous Cycles. Sociologia Ruralis, v. 54, n. 4, p. 417-438, 2014.

FOGUESATTO, C. R.; ARTUZO, F. D.; LAGO, A.; MACHADO, J. A. D. Fatores Relevantes para a Tomada de Decisão dos Jovens no Processo de Sucessão Geracional na Agricultura Familiar. Revista Paranaense de Desenvolvimento-RPD, v. 37, n. 130 , p. 15-28, 2016.

FRANZEN, D. O. A colônia em crise: a questão do meio ambiente, da agricultura e da sucessão familiar em debate no município de Itapiranga (1926-1960). DRdDesenvolvimento Regional em debate, ano 4, n. 1, p. 63-83, 2014.

GIL, A. C. Métodos e técnicas de pesquisa social. 6 ed. São Paulo: Atlas, 2008.

HILLESHEIM, L. P.; VIZZOTTO, M. A contribuição da formação por alternância na sucessão da agricultura familiar. Revista Eletrônica em Gestão, Educação e Tecnologia Ambiental, v. 19, n. 1, p. 03-08, 2015.

HUTSON, J. Fathers and sons: family farms, family businesses and the farming industry. Sociology, v. 21, n. 2, p. 215-229, 1987.

IBGE - Instituto Brasileiro de Geografia e Estatística. Censo Agropecuário Agricultura familiar - Brasil, grandes regiões e unidades da federação. 2006. Disponível em: http://www.ibge.gov.br/home/estatistica/economia/agropecuaria/censoagro/agri_famil iar_2006_2/default.shtm. Acesso em: 01 jun. 2017.

KISCHENER, M. A.; KIYOTA, N.; PERONDI, M. A. Sucessão geracional na agricultura familiar: lições apreendidas em duas comunidades rurais. Mundo Agrario, v. 16, n. 33, 2015.

LACERDA, T. F. N.; MARQUES, P. E. M. Agricultura orgânica, representação territorial e reprodução social da agricultura familiar. Ruris, v. 2, n. 2, p. 137-158, 2008.

LEONARD, B.; KINSELLA, A.; O'DONOGHUE, C.; FARRELL, M.; MAHON, M. Policy drivers of farm succession and inheritance. Land Use Policy, v. 61, p. 147-159, 2017.

MARTINS, R. M.; FUTEMMA, C. O jovem e o turismo rural: o caso do assentamento Ipanema, estado de São Paulo. Sociedade e Desenvolvimento Rural, v. 6, n. 1, 2012.

MARTINS, S. A. Juventude e juventude do campo: algumas considerações. Revista Faz Ciência, v. 9, n. 9, p. 237-256, 2007.

MATTE, A.; CHECHI, L.; BOSCARDIN, M.; SPANEVELLO, R. S.; ANDREATTA, T. Fatores condicionantes a permanência ou saída dos filhos em propriedades de agricultura e pecuária familiar no Rio Grande do Sul. In: XLVI Congresso da Sociedade Brasileira de Economia, Administração e Sociologia Rural, 2014, Goiânia. Anais... 
MATTE, A.; SPANEVELLO, R. M.; ANDREATTA, T. Perspectivas de sucessão em propriedades de pecuária familiar no município de Dom Pedrito-RS. Holos, v. $1, p$. 144-159, 2015.

MELLO, M. A.; ABRAMOVAY, R.; SILVESTRO, M. L.; DORIGON, C.; FERRARI, D. L.; TESTA, V. M. Sucessão hereditária e reprodução social da agricultura familiar. Agricultura em São Paulo, v. 50, n. 1, p. 11-24, 2003.

MENDONÇA, K. F. C.; RIBEIRO, E. M.; GALIZONI, F. M.; AUGUSTO, H. A. Formação, sucessão e migração: trajetórias de duas gerações de agricultores do Alto Jequitinhonha, Minas Gerais. Revista Brasileira de Estudos de População, v. 30, n. 2, p. $445-463,2013$

MERA, C. M. P.; NETTO, C. G. A. M. População rural na Região do Alto Jacuí/RS: análise sob a perspectiva do desenvolvimento agrícola. Campo-Território: revista de geografia agrária, v. 7, n. 14, p. 1-35, 2012.

MERA, C. M. P.; NETTO, C. G. A. M. Diminuição da população rural na região do Alto Jacuí/RS: análise sob a perspectiva dos segmentos rurais. Desenvolvimento em Questão, ano 12, n. 27, p. 216-263, 2014.

MISHRA, A. K.; EL-OSTA, H. S.; SHAIK, S. Succession Decisions in U.S. Family Farm Businesses. Journal of Agricultural and Resource Economics, v. 35, n. 1, p. 133-152, 2010.

OLIVEIRA, D.; SCHNEIDER, S. O futuro das unidades familiares: uma análise das possibilidades de sucessão hereditária entre os agricultores ecologistas de Ipê (RS). Novos Cadernos NAEA, v. 12, n. 2, p. 149-174, 2010.

PAIXÃO, M. E.; MERA, C. M. P.; DIVERIO, T. S. M. Reprodução da agricultura familiar frente ao modelo de desenvolvimento agrícola regional. Campo-Território: revista de geografia agrária, v. 10, n. 20, p. 153-179, 2015.

PELEGRINI, G.; GAZOLLA, M. A agroindustrialização como estratégia de reprodução social da agricultura familiar. Estudos Sociedade e Agricultura, v. 17, n. 2, p. 332-378, 2009.

PEREIRA, J. L. G. Educação, gênero e os projetos de vida dos jovens rurais de Baixada de Salinas (RJ). Ruris, v. 2, n. 2, p. 71-97, 2008.

PEREIRA, V. G.; REIS, L. S.; OLIVEIRA, M. L. S. Abordagem sobre os processos sucessórios do campesinato a partir das relações de gênero. Revista Latinoamericana de Geografia e Gênero, v. 3, n. 2, p. 87-97, 2012.

REDIN, E. Dentro e fora da porteira - os elementos condicionantes na estratégia de reprodução dos agricultores familiares fumageiros. Extensão Rural, Santa Maria, ano XVIII, n. 22, p. 67-102, 2011. Disponível em: https://periodicos.ufsm.br/extensaorural/article/view/5649.

REDIN, E. Família rural e produção de tabaco: estratégias de reprodução social em Arroio do Tigre/RS. 305 f. Tese (Doutorado em Extensão Rural) - Programa de 
Pós-Graduação em Extensão Rural, Universidade Federal de Santa Maria, Santa Maria, 2015.

SARON, F. A.; HESPANHOL, A. N. Agricultura familiar e dinâmica rural no município de Urânia-SP: limites e possibilidades para a reprodução social. Campo-Território: revista de geografia agrária, v. 7, n. 13, p. 228-247, 2012.

SAVIAN, M. Sucessão geracional: garantindo-se renda continuaremos a ter agricultura familiar? Revista Espaço Acadêmico, v. 14, n. 159, p. 97-106, 2014.

SCHNEIDER, S. Teoria social, agricultura familiar e pluriatividade. Revista Brasileira de Ciências Sociais, v. 18, n. 51, p. 99-121, 2003.

SCHNEIDER, S.; NIEDERLE, P. A. Agricultura familiar e teoria social: a diversidade das formas familiares de produção na agricultura. In: Savanas: desafios e estratégias para o equilíbrio entre sociedade, agronegócio e recursos naturais, 2008, Planaltina, DF. Embrapa Cerrados, Anais... p. 989-1014.

SEGUNDO e SILVA, P.; DINIZ FILHO, E. T.; MARACAJÁ, V. P. B. B.; MARACAJÁ, P. B.; PEREIRA, T. F. C. Agricultura familiar: um estudo sobre a juventude rural no município de Serra do Mel - RN. Revista Verde, v. 1, n. 1, p. 54-66, 2006.

SILVA, M. C.; WIZNIEWSKY, J. G. A produção do artesanato, como estratégia de reprodução na agricultura familiar na comunidade Vila Progresso no Município de Caçapava do Sul-RS. Extensão Rural, Santa Maria, v. 18, n. 21, p. 17-35, 2011. Disponível em: https://periodicos.ufsm.br/extensaorural/article/view/5568.

SILVA, T. M.; NETTO, C. G. A. M.; SILVA, L. X. Processo de reprodução social da agricultura familiar em Praia Grande (SC): dinâmicas demográficas e ocupacionais. Estudos Sociedade e Agricultura, v. 21, n. 1, p. 58-83, 2013.

SOUZA, S. B.; DOULA, S. M.; CARMO, P. M. Jovens rurais da Zona da Mata Mineira e projetos de vida profissional. Redes, v. 21, n. 1, p. 233-249, 2016.

SPANEVELLO, R. M. A dinâmica sucessória na agricultura familiar. 2008. 236f. Tese (Doutorado em Desenvolvimento Rural) - Programa de Pós-Graduação em Desenvolvimento Rural, Universidade Federal do Rio Grande do Sul.

SPANEVELLO, R.; AZEVEDO, L. F.; VARGAS, L. P.; MATTE, A. A migração juvenil e implicações sucessórias na agricultura familiar. Revista de Ciências Humanas, v. 45, n. 2, p. 291-304, 2011.

SUESS-REYES, J.; FUETSCH, E. The future of family farming: A literature review on innovative, sustainable and succession-oriented strategies. Journal of Rural Studies, v. 47, p. 117-140, 2016.

TONELLI, M. J.; CALDAS, M. P.; LACOMBE, B. M. B.; Tinoco, T. Produção acadêmica em recursos humanos no Brasil: 1991-2000. Revista de Administração de Empresas, v. 43, n. 1, p. 105-122, 2003. 
WANDERLEY, M. N. B. Jovens rurais de pequenos municípios de Pernambuco: que sonhos para o futuro. In: CARNEIRO, M. J.; CASTRO, E. G. C. (Orgs.). Juventude rural em perspectiva. Rio de Janeiro: Mauad X, 2007.

WAISELFISZ, J. J. Mapa da violência III. Brasília: UNESCO, 2002.

WEISHEIMER, N. A situação juvenil na agricultura familiar. 2009. 331f. Tese (Doutorado em Sociologia) - Programa de Pós-Graduação em Sociologia, Universidade Federal do Rio Grande do Sul.

WINCK, C. A.; PASQUA, S. D.; FISCHER, A.; GIANEZINI, M. Processo sucessório em propriedades rurais na região Oeste de Santa Catarina. Revista da Universidade Vale do Rio Verde, v. 11, n. 2, p. 115-127, 2013.

WOORTMANN, E. F.; Herdeiros, Parentes. Compadres: colonos do Sul e sitiantes do Nordeste. São Paulo-Brasília: Hucitec, 1995. 